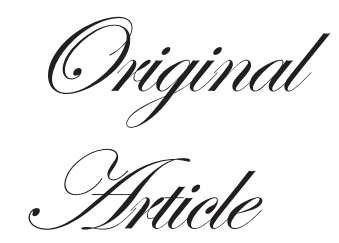

\title{
Profile of patients with incidentally detected non- alcoholic fatty liver disease (IDNAFLD) in coastal eastern India
}

\author{
Shivaram Prasad Singh ${ }^{1}$, Sanjib Kumar Kar ${ }^{1}$, Manas Kumar \\ Panigrahi $^{1}$, Bijay Misra ${ }^{1}$, Kaumudee Pattnaik ${ }^{2}$, Pallavi Bhuyan ${ }^{2}$, \\ Chudamani Meher ${ }^{3}$, Omprakash Agrawal ${ }^{3}$, Niranjan Rout ${ }^{4}$, \\ Manorama Swain ${ }^{5}$
}

\section{ABSTRACT}

Department of Gastroenterology ${ }^{1}$, Pathology ${ }^{2}$ and Biochemistry ${ }^{5}$, S.C.B. Medical College Department of Radiology ${ }^{3}$, Beam Diagnostics Centre, Bajrakabati Road

Department of Oncopathology $y^{4}$ A.H.Regional Cancer Center, Cuttack 753007, India.

\section{Correspondence:}

Dr Shivaram Prasad Singh

Email:scb_gastro_dept@hotmail.com
Background and Aim: Non-alcoholic fatty liver disease (NAFLD) has emerged as the commonest hepatic problem in both developed and developing countries. This study was conducted to delineate the clinical profile of incidentally detected NAFLD patients.

Methods: A retrospective analysis of clinical, biochemical and histological parameters was performed for 632 patients in whom fatty liver was diagnosed by ultrasonography during 2006-2010. Every patient's clinical presentation, history, liver function tests, blood sugar, lipid profile, ultrasonogram, histology and other relevant investigations were analyzed. Patients referred for transaminitis or overt chronic liver disease were excluded.

Results: Out of 632 consecutive NAFLD patients, 484 (76.6\%) were males and 148 (23.4\%) were females. Mean age of our patients was $42.44 \pm 10.18$ years. Their mean body mass index (BMI) was $26.14 \pm 3.38 \mathrm{~kg} / \mathrm{m}^{2}$. Obesity (BMI>25), diabetes mellitus, hypertension, hyperlipidemia, metabolic syndrome and insulin resistance were present in $61.7 \%, 15.2 \%$, $19.8 \%, 62.0 \%, 40.0 \%$, and $54.4 \%$ patients, respectively. SGOT and SGPT were elevated in $38.29 \%$ and $55.1 \%$ patients, respectively. The common primary diseases for which these patients sought consultation were non-ulcer dyspepsia (NUD) (54.5\%) and irritable bowel syndrome (IBS) (29.4\%). Of the 64 patients who underwent liver biopsy, one-fourth had definite NASH while one-third patients had fibrosis.

Conclusion: In India, incidentally detected NAFLD (IDNAFLD) patients are predominantly middle aged males, most of whom are not lean. Most of these patients seek consultation for functional bowel disease.

KEYWORDS: BMI, transaminitis, metabolic syndrome, ultrasonography, NASH, fibrosis

\section{Introduction}

With the increasing prevalence of obesity, diabetes and metabolic syndrome (MS) in the general population, nonalcoholic fatty liver disease (NAFLD) has emerged as a major hepatic problem worldwide. There is a wide variation in the reported prevalence of NAFLD in Asian countries on account of the variable defining criteria for NAFLD, and the 
inhomogeneous study population in different studies. The prevalence is estimated to be $15 \%-46 \%$ in western countries $^{1-3}$ and 8\%-40\% in Asian countries. ${ }^{4-8}$ Although NAFLD was earlier considered relatively benign, it has now become clear that it may progress to cirrhosis, liver failure and hepatocellular carcinoma. ${ }^{9-11}$

Another concern regarding NAFLD is its strong association with MS, ${ }^{12}$ with insulin resistance (IR) playing a key pathogenic role. ${ }^{13}$ In India, there has been a surge in the incidence of obesity, diabetes mellitus, and MS possibly due to physical inactivity, economic growth and environmental factors. ${ }^{14-16}$ In fact, NAFLD is now considered the hepatic manifestation of MS. ${ }^{17}$

Although NAFLD seems ubiquitous, there is paucity of data on the clinical profile of general patients with NAFLD seen by physicians, since the published profile is based on selected subset of patients who may be having more severe NAFLD. Our study aimed to assess the clinical, biochemical and histological profile of patients with incidentally detected NAFLD (IDNAFLD) during a gastrointestinal work-up.

\section{Materials and methods}

Study design

This is a retrospective study to evaluate the clinical, biochemical and histological profile of IDNAFLD.

\section{Subjects}

\section{Inclusion criteria}

Consecutive patients attending a gastroenterology clinic for different gastrointestinal complaints in whom liver steatosis was diagnosed by ultrasonography (USG) were included provided relevant data pertaining to clinical, anthropometric, metabolic and biochemical profile were available.

\section{Exclusion criteria}

Alcohol consumption of $\geq 20 \mathrm{~g} /$ day (as evident from patients' confession or interview of close relatives), presence of hepatitis $\mathrm{B}$ or $\mathrm{C}$ virus infection or other liver diseases such as autoimmune hepatitis, Wilson's disease, á ${ }_{1}$-antitrypsin deficiency, haemochromatosis, and patients on medications producing steatosis within the past 6 months were excluded from the study. Patients referred for increased transaminases or with overt chronic liver disease were also excluded.

\section{Methods}

During the study period, a total of 16,225 patients with various gastrointestinal complaints were seen; of these 3426 were subjected to USG for evaluation of various gastrointestinal complaints. A total of 362 patients with overt liver diseases were excluded; of the remaining 3064 patients, USG detected fatty liver in 718 patients. Out of these 55, 18 and 13 patients were excluded for inadequate data, HBV infection and referral for transaminitis, respectively. The remaining 632 patients with complete biochemical and metabolic parameters constituted the study subjects.

All patients had been evaluated with thorough clinical history and examination. In all the subjects, anthropometric measurements including height, weight, waist and hip circumferences were recorded. All patients had been subjected to biochemical and haematological work-up especially liver function test (LFT), lipid profile, fasting serum insulin, fasting blood glucose (FBG) and oral glucose tolerance test (OGTT) in the same laboratory by standard laboratory methods. Liver biopsy was performed after informed consent in only those patients who agreed for it using an 18 gauge Menghini's aspiration needle. The study was approved by the Institutional Ethics Committee of the Kalinga Gastroenterology Foundation, Cuttack, India.

\section{Definitions}

For serum lipids, we referred to the National Cholesterol Education Program-Adult Treatment Panel III (NCEP-ATP III) guidelines. ${ }^{18,19}$ The diagnosis of type II diabetes, impaired glucose tolerance (IGT), impaired fasting glycaemia (IFG) were made on the basis of the American Diabetes Association (ADA) criteria. ${ }^{20}$ The normal range of alanine aminotransferase (ALT) and aspartate aminotransferase (AST) was 0-40 IU/L. Resting blood pressure $\geq 140 / 90 \mathrm{mmHg}$ or treatment with antihypertensive drugs indicated hypertension. The normal range for fasting insulin level was 6-27i $/ \mathrm{mL}$ and IR was defined as homeostasis model assessment of IR (HOMA-IR) value $\geq 2 .{ }^{21}$

Obesity guidelines based on western populations markedly underestimate the risk among Asians who have greater body fat at a given body mass index (BMI). ${ }^{19,22}$ We referred to the consensus guidelines for Asian Indians for BMI and abdominal obesity. ${ }^{22}$ Overweight and obesity were defined as BMI $\geq 23$ $\mathrm{kg} / \mathrm{m}^{2}$ and $\geq 25 \mathrm{~kg} / \mathrm{m}^{2}$, respectively. Prevalence of MS in our study was assessed on the basis of the 2001 modified NCEP- 
ATP III-2 guidelines..$^{22}$ Since we did not have measurements of waist and hip circumference in a significant number of patients, we replaced abdominal obesity with BMI $>25 \mathrm{~kg} / \mathrm{m}^{2}$ in the NCEPATP III-2 criteria as a surrogate criterion for MS, as done by Madan et al. ${ }^{23}$

\section{Ultrasonographic examination}

Diagnosis and grading of liver steatosis was done by using USG by two radiologists who did not have information about the patients. Fat infiltration in the liver was described according to Saadeh et al. ${ }^{24}$

\section{Histological assessment}

Liver biopsy specimens were evaluated by an experienced pathologist unaware about the patients. Histological features were analysed according to the method suggested by Kleiner et al. ${ }^{25}$

\section{Statistical analysis}

The results were displayed in tables with categorical variables presented as numbers and percentages, and the continuous variables presented as mean \pm standard deviation (SD). The data were analysed using SPSS version 17 package. Z-test was used to compare proportions among the groups and $\mathrm{p}$ value $<0.05$ was considered significant.

\section{Results}

Of the 718 patients diagnosed with fatty liver on USG, 55, 18 and 13 patients were excluded from the study due to inadequate data, HBV infection and referral for transaminitis, respectively. Of the remaining 632 patients, 484 (76.6\%) were men and 148 $(23.4 \%)$ women, with sex ratio of 3:1. The age range was 17-80 years (mean $42.44 \pm 10.18$ years). Most patients belonged to the fourth and fifth decades of life (Figure 1). These patients attended the clinic not for NAFLD, but for a variety of gastrointestinal symptoms. The various diseases associated with these patients with IDNAFLD are shown in Table 1. A majority of patients presented with functional bowel disease (FBD)—non-ulcer dyspepsia (NUD) $(345 ; 54.6 \%)$ and irritable bowel syndrome (IBS) $(186 ; 29.4 \%)$.

The mean values of biochemical parameters including lipid profile and LFT are given in Table 2. Hepatomegaly was found

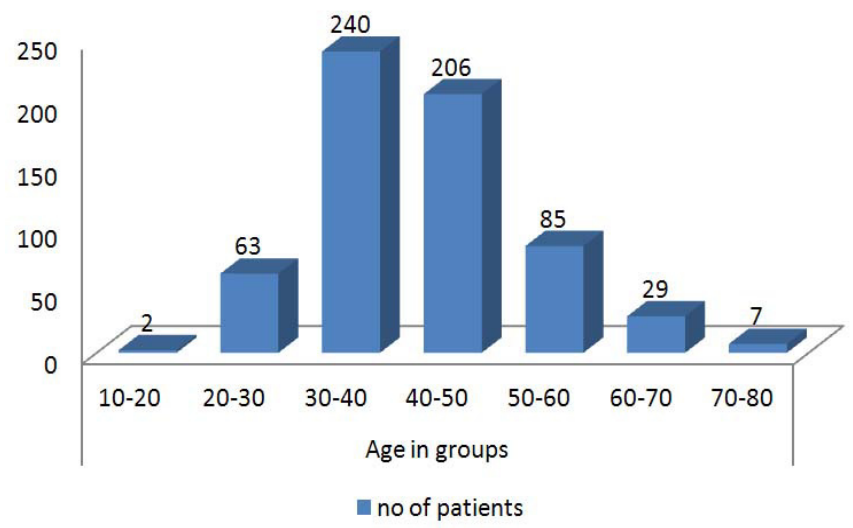

Figure 1: Age-wise distribution of patients with fatty liver disease

Table 1: Diseases associated with IDNAFLD

\begin{tabular}{lcc}
\hline Clinical diagnosis & $\begin{array}{c}\text { No. of patients } \\
(\mathbf{n = 6 3 2})\end{array}$ & $\begin{array}{c}\text { Percentage of patients } \\
(\mathbf{\%})\end{array}$ \\
\hline NUD & 345 & 54.6 \\
IBS & 186 & 29.4 \\
Peptic ulcer & 31 & 4.9 \\
GERD & 27 & 4.3 \\
Post-ulcer dyspepsia & 8 & 1.3 \\
Biliary colic & 8 & 1.3 \\
Pancreatitis & 4 & 0.6 \\
Carcinoma stomach & 3 & 0.5 \\
Intestinal tuberculosis & 3 & 0.5 \\
Others $^{\mathrm{a}}$ & 17 & 2.7 \\
\hline
\end{tabular}

${ }^{a}$ Urinary tract infection, ureteric colic, idiopathic pedal swelling, unexplained hyperbilirubinaemia without transaminitis, inflammatory bowel disease, carcinoma rectum, gastroenteritis, ascariasis, appendicitis and Mallory-Weiss tear.

NAFLD=non-alcoholic fatty liver disease; IBS=irritable bowel syndrome; GERD=gastroesophageal reflux disesease; $N U D=n o n$ ulcer dyspepsia

in only $36(5.7 \%)$ patients. Hyperbilirubinaemia $(>1.2 \mathrm{mg} / \mathrm{dL})$ was present in $82(13 \%)$ patients and elevated SGOT and SGPT levels in $242(38.3 \%)$ and $348(55.1 \%)$ patients, respectively.

Using the consensus guidelines for Asian Indians, normal BMI was found in 101 (16\%) patients, 141 (22.3\%) were overweight, while 390 (61.7\%) were obese. Using the ADA criteria, diabetes mellitus, i.e. FBG $\geq 126 \mathrm{mg} / \mathrm{dL}$ and $\mathrm{OGTT} \geq 200$ $\mathrm{mg} / \mathrm{dL}$ were found in $52(8.2 \%)$ and $73(11.6 \%)$ patients, respectively. Impaired FBG was present in $110(17.4 \%)$ patients, and impaired OGTT in 129 (20.4\%) patients. Overall, diabetes was present in $96(15.2 \%)$ patients, hypertension in 125 (20.4\%) patients and hyperlipidaemia in $392(62 \%)$ patients. MS was found in $255(40.3 \%)$ patients. Prevalence of the different components of MS has been shown in Figure 2. As fasting insulin was not tested in all the patients, we evaluated 386 patients for IR calculated as HOMA-IR. However, IR was found in $210(54.4 \%)$ patients. 
Table 2: Baseline demographic, biochemical and ultrasonographic parameters of patients with IDNAFLD

\begin{tabular}{|c|c|}
\hline Parameters & Values \\
\hline Age (years)* & $42.44 \pm 10.18$ \\
\hline $\mathrm{BMI}\left(\mathrm{kg} / \mathrm{m}^{2}\right)^{*}$ & $26.13 \pm 3.38$ \\
\hline $\mathrm{FBG}(\mathrm{mg} / \mathrm{dL}) *$ & $95.38 \pm 27.16$ \\
\hline PGBS $(\mathrm{mg} / \mathrm{dL}) *$ & $137.84 \pm 54.64$ \\
\hline $\mathrm{TG}(\mathrm{mg} / \mathrm{dL}) *$ & $199.17 \pm 128.96$ \\
\hline Cholesterol $(\mathrm{mg} / \mathrm{dL})^{*}$ & $184.35 \pm 39.48$ \\
\hline $\operatorname{HDL}(\mathrm{mg} / \mathrm{dL}) *$ & $39.80 \pm 7.85$ \\
\hline $\mathrm{LDL}(\mathrm{mg} / \mathrm{dL})^{*}$ & $107.63 \pm 32.70$ \\
\hline VLDL (mg/dL) & $36.63 \pm 19.021$ \\
\hline TC/HDL* & $4.72 \pm 1.06$ \\
\hline Total bilirubin $(\mathrm{mg} / \mathrm{dL})^{*}$ & $0.88 \pm 0.45$ \\
\hline SGOT $(\mathrm{U} / \mathrm{L})^{*}$ & $40.71 \pm 22.53$ \\
\hline SGPT (U/L)* & $52.98 \pm 36.67$ \\
\hline $\mathrm{SAP}(\mathrm{U} / \mathrm{L}) *$ & $215.51 \pm 77.00$ \\
\hline Male sex & $484(76.6 \%)$ \\
\hline Normal BMI $\left(<23 \mathrm{~kg} / \mathrm{m}^{2}\right)$ & $101(16.0 \%)$ \\
\hline Overweight (23-24.99 kg/m²) & $141(22.3 \%)$ \\
\hline Obesity $\left(>25 \mathrm{~kg} / \mathrm{m}^{2}\right)$ & $390(61.7 \%)$ \\
\hline Low SES (<INR 2500/month) & $112(17.7 \%)$ \\
\hline Middle SES (INR 2500-20,000/month) & $420(66.5 \%)$ \\
\hline High SES (>INR 20,000/month) & $100(15.8 \%)$ \\
\hline Hypertension & $125(20.4 \%)$ \\
\hline Diabetes & $96(15.2 \%)$ \\
\hline Impaired FBG (mg/dL) & $110(17.4 \%)$ \\
\hline Impaired OGTT (mg/dL) & $129(20.4 \%)$ \\
\hline Hyperlipidaemia & $392(62.0 \%)$ \\
\hline Hyperbilirubinaemia ( $>1.2 \mathrm{mg} / \mathrm{dL}$ ) & $82(13.0 \%)$ \\
\hline $\operatorname{SGOT}(>40 \mathrm{U} / \mathrm{L})$ & $242(38.3 \%)$ \\
\hline $\operatorname{SGPT}(>40 \mathrm{U} / \mathrm{L})$ & $348(55.1 \%)$ \\
\hline Hepatomegaly & $36(5.7 \%)$ \\
\hline Mild fatty liver (USG) & $491(77.7 \%)$ \\
\hline Moderate fatty liver (USG) & $135(21.4 \%)$ \\
\hline Severe fatty liver (USG) & $6(0.9 \%)$ \\
\hline
\end{tabular}

* mean \pm standard deviation

$B M I=$ body mass index; $F B G=$ fasting blood glucose; $P G B S=$ post glucose blood sugar; $T G=$ triglyceride; $H D L=$ high-density lipoprotein ; $L D L=$ low-density lipoprotein,$V L D L=$ very-low density lipoprotein; $T C / H D L=$ total cholesterol/high-density lipoprotein; $S G O T=$ serum glutamic oxaloacetic transaminase; SGPT=serum glutamic pyruvic transminase; $S A P=$ serum alkaline phosphatase; $S E S=$ socioeconomic status; $O G T T=$ oral glucose tolerance test; $U S G=$ ultrasonography

Socioeconomic status (SES) of the patients was arbitrarily decided according to the monthly income of the family. It was taken as low if the monthly income was less than INR 2500 (US\$ 50), middle if the monthly income was between INR 2500 and INR 20,000 (US\$ 50-400) and high if the monthly income was more than INR 20,000 (US\$400). In our study, most patients $(66.5 \%)$ with fatty liver disease were from middle SES, followed by low (17.7\%) and high (15.8\%) SES (Table 2).

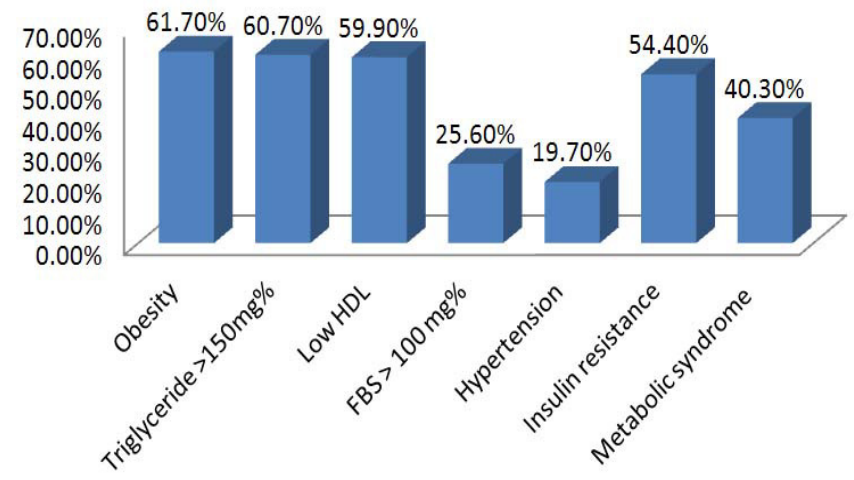

Figure 2: Prevalence of individual components of metabolic syndrome (MS)

$\mathrm{TG}=$ triglyceride; $\mathrm{HDL}=$ high-density lipoprotein; $\mathrm{FBG}=$ fasting blood glucose; $\mathrm{IR}=$ insulin resistance

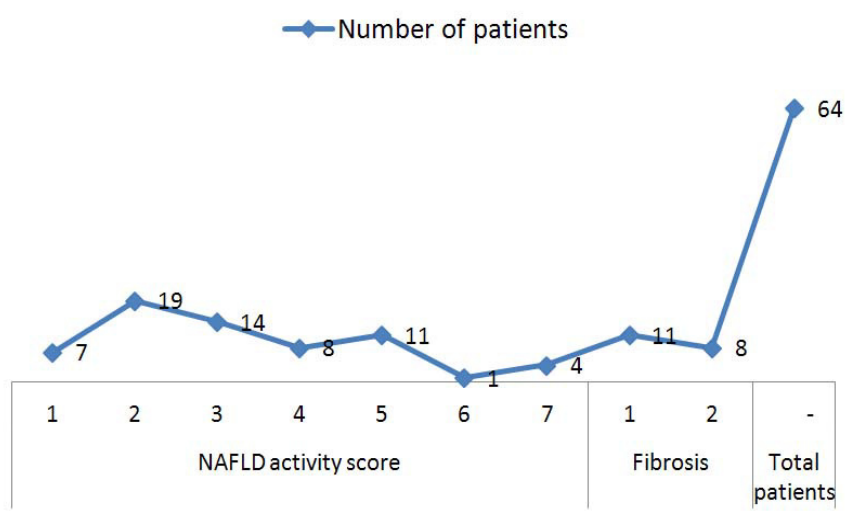

Figure 3: Histological profile of biopsied patients NAFLD=non-alcoholic fatty liver disease

Sixty-four consenting patients had undergone liver biopsy; details of histological findings are shown in Figure 3. Of 64 patients who had liver biopsy, steatosis alone was present in $26(40.6 \%)$, borderline NASH in $22(34.37 \%)$ and definite NASH in $16(25 \%)$ patients. Analysis of risk factors revealed that advanced age alone ( $>40$ years), $(\mathrm{OR}=3.667,95 \%$ CI: $1.096-$ $12.290, \mathrm{p}=0.043$ ) was significantly associated with high grades of inflammation. MS and hypertension were commoner in patients with severe inflammation but the differences did not attain statistical significance (Table 3). Most patients had either absent or minimal fibrosis. Forty-five (70.3\%), 11 (17.1\%) and 8 (12.5\%) patients had stage 0 , stage 1 and stage 2 fibrosis, respectively. No patient had advanced fibrosis or cirrhosis. On evaluation of risk factors, only triglyceride (TG) level $>150 \mathrm{mg} \%$ and hypertension were more common among patients with fibrosis (Table 4). Further, in patients with transaminitis (46/ 64), steatosis, borderline NASH, definite NASH and fibrosis were found in $43.47 \%, 34.78 \%, 21.73 \%$ and $19.56 \%$ patients, respectively. However, in the steatosis sans transaminitis group, borderline NASH and definite NASH were found in one-third 
Table 3: Factors associated with histological NASH in biopsied patients with IDNAFLD

\begin{tabular}{llll}
\hline Variables & $\begin{array}{l}\text { With NASH } \\
(\mathbf{n = 1 6})\end{array}$ & $\begin{array}{l}\text { Without NASH p value } \\
(\mathbf{n = 4 8})\end{array}$ & \\
\hline Age $(>40$ years) & $11(68.8 \%)$ & $18(37.5 \%)$ & 0.043 \\
Male sex & $11(68.8 \%)$ & $41(85.4 \%)$ & 0.156 \\
BMI $\left(>25 \mathrm{~kg} / \mathrm{m}^{2}\right)$ & $8(50.0 \%)$ & $33(68.8 \%)$ & 0.232 \\
Diabetes & $1(6.3 \%)$ & $8(16.7 \%)$ & 0.430 \\
Hypertension & $6(32.5 \%)$ & $8(16.7 \%)$ & 0.095 \\
Hyperlipidaemia & $10(62.5 \%)$ & $21(43.8 \%)$ & 0.252 \\
MS & $10(62.5 \%)$ & $16(33.3 \%)$ & 0.076 \\
Hepatomegaly & $2(12.5 \%)$ & $3(6.3 \%)$ & 0.592 \\
FBG $(>100 \mathrm{mg} \%)$ & $5(31.5 \%)$ & $11(68.0 \%)$ & 0.519 \\
TG $(>150 \mathrm{mg} \%)$ & $10(62.5 \%)$ & $25(52.1 \%)$ & 0.508 \\
Cholesterol $(>200 \mathrm{mg} \%)$ & $4(25.0 \%)$ & $10(20.8 \%)$ & 0.736 \\
HDL $(<40 \mathrm{mg} \%)$ & $7(43.8 \%)$ & $13(65 \%)$ & 0.229 \\
SGOT $(>40 \mathrm{mg} \%)$ & $10(62.5 \%)$ & $24(50 \%)$ & 0.564 \\
SGPT $(>40 \mathrm{mg} \%)$ & $10(62.5 \%$ & $35(72.9 \%)$ & 0.530 \\
\hline
\end{tabular}

NASH=non-alcoholic steatohepatitis; $B M I=$ body mass index; $M S=$ metabolic syndrome; $F B G=$ fasting blood glucose; $T G=$ triglyceride; $H D L=$ high-density lipoprotein; $S G O T=$ serum glutamic oxaloacetic transaminase; $S G P T=$ serum glutamic pyruvic transminase; IDNAFLD=incidentally detected non-alcoholic fatty liver disease

Table 4: Factors associated with histological fibrosis in biopsied patients with IDNAFLD

\begin{tabular}{llll}
\hline Variables & $\begin{array}{l}\text { With fibrosis } \\
(\mathbf{n = 1 9 )}\end{array}$ & $\begin{array}{l}\text { Without fibrosis p value } \\
(\mathbf{n = 4 5})\end{array}$ \\
\hline Age $(>40$ years) & $10(52.6 \%)$ & $19(42.2 \%)$ & 0.584 \\
Male sex & $14(52.6 \%)$ & $38(84.4 \%)$ & 0.318 \\
BMI $\left(>25 \mathrm{~kg} / \mathrm{m}^{2}\right)$ & $10(52.6 \%)$ & $31(68.9 \%)$ & 0.260 \\
Diabetes & $1(5.3 \%)$ & $8(17.8 \%)$ & 0.260 \\
Hypertension & $7(36.5 \%)$ & $7(15.6 \%)$ & 0.096 \\
Hyperlipidaemia & $11(57.9 \%)$ & $25(44.4 \%)$ & 0.415 \\
MS & $10(52.6 \%)$ & $16(35.6 \%)$ & 0.268 \\
Hepatomegaly & $1(5.3 \%)$ & $4(9.1 \%)$ & 1.000 \\
FBG $(>100 \mathrm{mg} \%)$ & $5(26.3 \%)$ & $11(24.4 \%)$ & 1.000 \\
TG (>150 mg\%) & $14(73.7 \%)$ & $21(46.7 \%)$ & 0.058 \\
Cholesterol (>200 mg\%) & $4(21.1 \%)$ & $10(22.2 \%)$ & 1.000 \\
HDL $(<40 \mathrm{mg} \%)$ & $13(68.4 \%)$ & $31(68.9 \%)$ & 1.000 \\
SGOT (>40 mg\%) & $12(63.2 \%)$ & $22(48.9 \%)$ & 0.412 \\
SGPT $(>40 \mathrm{mg} \%)$ & $14(73.7 \%)$ & $31(68.9 \%)$ & 0.773 \\
\hline
\end{tabular}

BMI=body mass index; $M S=$ metabolic syndrome; $F B G=$ fasting blood glucose; TG=triglyceride; $H D L=$ high-density lipoprotein; $S G O T=$ serum glutamic oxaloacetic transaminase; $S G P T=$ serum glutamic pyruvic transminase; IDNAFLD=incidentally detected nonalcoholic fatty liver disease

patients equally, but fibrosis was found in $27.7 \%$ patients. On comparison of histological features of patients with and without transaminitis, there was no significant difference in NASH activity score or fibrosis. Since NUD and IBS were the two commonest associated disorders, NUD constituting $54.5 \%$ and IBS $29.4 \%$ of the total NAFLD subjects, the two groups were compared vis-à-vis the different metabolic, biochemical and histological parameters. Except for significantly higher TG levels in patients with NUD (211.60+154.31 vs. $183.06+88.27$; $\mathrm{p}=0.02$ ), there was no significant difference on comparing other parameters.

\section{Discussion}

Although NAFLD has emerged as the commonest liver problem worldwide and is found in up to one-third of the general population,,$^{1,4,7,26,27}$ there is little information on the true profile of patients with NAFLD in clinical practice. Most studies for diagnosis of NAFLD are based on selected subset of patients with MS or transaminitis, ${ }^{6,8,23,28-29}$ although only about half of the patients with NAFLD have transaminitis and patients without transaminitis can harbour advanced disease. ${ }^{30,31}$ Thus, the profile of NAFLD in the published literature may in fact present a skewed picture.

In our study, transaminases were elevated in $55 \%$ of patients with NAFLD - higher compared to other Indian studies, ${ }^{6,8}$ but lower than the western studies..$^{9,32}$ Further, similar to other studies, ${ }^{33}$ there was no difference in necroinflammatory activity or fibrosis between the transaminitis and non-transaminitis group. Similarly, a Turkish study showed that while only $64 \%$ of patients with transaminitis had NASH, $68 \%$ of patients with normal aminotransferase level too had NASH. ${ }^{34}$ Our findings reaffirm that transaminitis is not a reliable marker of NASH, and ALT levels should not guide the decision regarding liver biopsy.

There is scanty information on the underlying clinical diseases associated with NAFLD. ${ }^{5,35}$ In our study, most patients presented with FBD; NUD and IBS accounted for $84 \%$ patients (Table 1). Although the nature of this association of NAFLD with FBD is not clear, the most likely reason could be that the profile reflects the disease spectrum of patients who were subjected to USG. However, there may also be a cause-effect relationship between these luminal disorders and NAFLD. It has been shown that altered interactions between the gut microbiota and the host, produced by defective NLRP3 and NLRP6 inflammasome sensing, may govern the rate of progression of multiple MS-associated abnormalities. ${ }^{36}$ The association between IBS and NAFLD observed in our study may be due to the alterations in gut microbiota in patients with IBS. In a study by Pyleris et al., it was found that small intestinal bacterial overgrowth (SIBO) was present in $60 \%$ of patients with IBS with predominant diarrhoea in contrast to $27.3 \%$ without diarrhoea $(\mathrm{p}=0.004)$; Escherichia coli, Enterococcus 
spp. and Klebsiella pneumoniae were the most common isolates within patients with SIBO ${ }^{37}$ In another study by Sabaté et al., the frequency of positive breath tests was found to be higher in obese patients than in healthy subjects $(17.1 \%$ vs. $2.5 \%$; $\mathrm{p}=0.031)$, and on multivariate analysis, $\operatorname{SIBO}(\mathrm{p}=0.005)$ and presence of MS ( $\mathrm{p}=0.006$ ) were found to be independent risk factors for severe hepatic steatosis. Sabaté et al. concluded that the prevalence of bacterial overgrowth is higher in morbidly obese patients than in healthy subjects and is associated with severe hepatic steatosis. ${ }^{38}$

In a study by Polyzos et al., higher rates of anti-Helicobacter pylori IgG were observed in patients with NAFLD as compared to the control group, although there were no significant differences in steatosis grade, fibrosis stage, lobular or portal inflammation, or ballooning when patients with NAFLD were divided according to $\mathrm{H}$. pylori IgG seropositivity or [13]C-urea breath test positivity. The authors suggested that $\mathrm{H}$. pylori infection may represent another hit contributing to pathogenesis of NAFLD, though not to the progression from NAFLD to NASH. ${ }^{39}$ Another study by Takuma too has shown H. pylori infection as one of the independent risk factors for the development of NAFLD. ${ }^{40}$

Thus, H. pylori infection as well as intestinal bacterial flora might play a significant role in the pathogenesis of NAFLD in these patients, ${ }^{36-41}$ and there is a serious need to assess the role of gut microflora and $\mathrm{H}$. pylori infection in the pathogenesis of NAFLD or NASH, and their contribution to the overall burden of NAFLD in developing countries especially in lean patients with NASH.

The present study showed NAFLD to be a disease of middle age with mean age of $42.44 \pm 10.81$ years at presentation and men predilection - three-fourths $(76.6 \%)$ being male. We had reported earlier that the prevalence of NAFLD was two-folds higher among men. ${ }^{4}$ Mohan et al. and Pinidiyapathirage et al. too have reported the preponderance of men. ${ }^{7,42}$ However, Fernandes et al., ${ }^{43}$ and Haentjens et al. ${ }^{44}$ suggest that women especially those who are at increased risk of developing NAFLD. Spruss et al., too showed that female mice were more susceptible to NAFLD than male mice..$^{45}$ A recent Australian study has suggested that sex differences in adolescents with NAFLD are related to differences in adipose distribution and adipocytokines. ${ }^{46}$ The predominance of men in our study may also be explained by social discrimination towards women and psychosocial inhibition among them in seeking medical attention for their problems. A majority were from middle SES which probably reflects the overall SES of the study population.
In our study, the mean BMI was $26.13 \pm 3.38 \mathrm{~kg} / \mathrm{m}^{2} ; 22.3 \%$ and $61.7 \%$ patients were overweight and obese, respectively. Similar findings were seen in most other Indian studies with a median BMI value of $26.7 \mathrm{~kg} / \mathrm{m}^{2}$ with almost $60 \%-70 \%$ patients having obesity as defined by the Asia-Pacific criteria. ${ }^{8,23,28} \mathrm{An}$ exception to this is the Bengal study with very low BMI $\left(22.7 \pm 3.90 \mathrm{~kg} / \mathrm{m}^{2}\right) ;^{6}$ this may be because the study was carried out in an extremely underprivileged area; and as expected, the prevalence of NAFLD was only $8.7 \%$. The Bengal findings cannot be applied to other populations. Our patients with NAFLD had a lower mean value of BMI as compared to the western figures (30-38 kg/m²). ${ }^{3,9,32,47}$ Despite lower BMI, our patients had fatty liver, possibly due to characteristics of South Asian phenotype (i.e. greater propensity to IR and central obesity)..$^{15}$

Only $15 \%$ of our patients had diabetes, while another $17 \%$ had only IGT. A lower prevalence of diabetes (7\%-22\%) was also found in other Indian studies. ${ }^{6-8,23,28}$ This is in contrast to western figures - $38 \%$ cases of diabetes in NAFLD (UK) ${ }^{44}$ while among Americans, diabetes was associated with half of histologically proven patients with NAFLD. ${ }^{48}$

In our study, the prevalence of MS was $40.3 \%$; in contrast in the New Delhi study, of MS was found in only $20 \%$ of patients. ${ }^{23}$ This difference may be due to the higher FBG cutoff level of $>110 \mathrm{mg} \%$ for diagnosis of diabetes and the inclusion criterion of transaminitis in this study. Our study was USG-based and a more appropriate FBG cut-off level of $>100 \mathrm{mg} / \mathrm{dL}$ was used. Other studies ${ }^{28,32}$ have reported similar findings.

The pathogenesis of NAFLD involves a two-hit hypothesis. ${ }^{49}$ The first hit is steatosis, and the second hit leads to transformation from steatosis to steatohepatitis. IR is believed to play an important role in both these hits. ${ }^{50}$ In the present study, the prevalence of IR was only $54.4 \%$. In contrast, other Indian studies reported a higher frequency of $80 \%$ $83 \%, 23,28$ a lower cut-off value (IR $>1.64$ ) used in these studies may account for a higher prevalence of IR among them. ${ }^{23}$ In the present study, the mean serum TG and mean serum LDL levels are above the normal upper limit, while the mean serum HDL level is below the normal limit, signifying that most patients had dyslipidaemia - a known risk factor for fatty liver.

Histologically, steatosis was present in all patients; however, definite NASH was present in only $25 \%$ of patients, and fibrosis (grade I/II) was present in $29.68 \%$ of cases. However, fibrosis was present in $75 \%$ of patients with "definite NASH" and in $32 \%$ of patients with "borderline NASH". No 
evidence of cirrhosis was found. This is in contrast to the Bengal study in which NASH and cirrhosis were seen in $31 \%$ and $2.4 \%$ cases, respectively. ${ }^{6}$ However, other Indian studies have not reported advanced fibrosis, though definite NASH has been reported in over $50 \%$ of patients with NAFLD. ${ }^{23,28}$ Further, the histological features reported in these studies are less severe compared to those in the West, where advanced fibrosis or cirrhosis has been reported in up to $50 \%$ of NAFLD cohorts. ${ }^{9,31,51,52}$ This is possibly because these patients do not represent the general population with NAFLD, as they have greater dysglycaemia and obesity. Two recent studies also support this contention and have paradoxically reported advanced fibrosis (3/4) in only $6 \%-7 \%$ of patients with NAFLD. ${ }^{3,47}$ Comparing the variables between patients with NASH and patients without NASH, only advanced age was significantly associated with NASH. None of the other variables were associated with the presence of fibrosis.

In summary, the present study revealed that our Indian subjects with NAFLD were younger, had lower BMI, lower prevalence of diabetes mellitus and MS, but similar necroinflammatory activity score and fibrosis as compared to that reported in the West. Transaminitis is neither a reliable marker of NASH nor fibrosis and should not influence the decision for liver biopsy in these patients.

\section{Limitations}

- In the majority of patients, diagnosis of fatty liver was done on only the basis of USG findings whose sensitivity and specificity is observer-dependent. The difficulty in detecting the presence of fatty liver with USG is well known in morbidly obese patients, and when the degree of fat infiltration is $<33 \%$ of the hepatic content. ${ }^{24}$

- Defining obesity as BMI $>25 \mathrm{~kg} / \mathrm{m}^{2}$ may not be acceptable to many physicians. This could also be true for the use of BMI as a surrogate marker for waist circumference, which may not always be true. Indian subjects may have a normal BMI but an abnormal waist which is more closely related to central obesity rather than overall obesity.

- As the present study was clinic-based and not a crosssectional population study, the findings of this study may not be truly representative and applicable to the general population at large.

\section{Conclusions}

Despite the drawbacks, this is a unique attempt to characterize and define the profile of patients with IDNAFLD who are commonly encountered in clinical practice and constitute the bulk of the patients with NAFLD. Our findings have important clinical and public health implications. This study also evaluated and analysed the clinical diseases associated with NAFLD and observed that most of these patients sought consultation for FBD. Further, patients with IDNAFLD were predominantly men, most of whom were not lean. Only about half the patients had transaminitis. Prevalence of NAFLD appears to be substantially higher than that predicted on the basis of elevated ALT levels. Male sex, BMI, transaminitis and MS were independently associated with ultrasonographic severe fatty change. One-fourths of the patients with IDNAFLD had definite NASH on histology and one-thirds had mild fibrosis. Early detection, as well as steps to prevent the condition through lifestyle modification may halt the progression of a benign disease to advanced illness. It is important for physicians and general practitioners to be aware about the clinical, biochemical and histological profile of IDNAFLD which is such a common liver disorder.

\section{References}

1. Farrell GC, Larter CZ. Nonalcoholic fatty liver disease: from steatosis to cirrhosis. Hepatology. 2006;43:S99-S112.

2. Bedogni G, Miglioli L, Masutti F, Tiribelli C, Marchesini G, Bellentani S. Prevalence of and risk factors for nonalcoholic fatty liver disease: the Dionysos nutrition and liver study. Hepatology. 2005;42:44-52.

3. Williams CD, Stengel J, Asike MI, Torres DM, Shaw J, Contreras $\mathrm{M}$, et al. Prevalence of nonalcoholic fatty liver disease and nonalcoholic steatohepatitis among a largely middle-aged population utilizing ultrasound and liver biopsy: a prospective study. Gastroenterology. 2011;140:124-31.

4. Singh SP, Nayak S, Swain M, Rout N, Mallik RN, Agrawal O, et al. Prevalence of nonalcoholic fatty liver disease in coastal eastern India: a preliminary ultrasonographic survey. Trop Gastroenterol. 2004;25:76-9.

5. Singh SP, Agrawal O, Meher C. Nonalcoholic fatty liver disease (NAFLD) in Orissa. Orissa Physician Journal. 2005;1:8-15.

6. Das K, Das K, Mukherjee PS, Ghosh A, Ghosh S, Mridha AR, et al. Nonobese population in a developing country has a high prevalence of nonalcoholic fatty liver and significant liver disease. Hepatology. 2010;51:1593-602.

7. Mohan V, Farooq S, Deepa M, Ravikumar R, Pitchumoni CS. Prevalence of non-alcoholic fatty liver disease in urban south Indians in relation to different grades of glucose intolerance and metabolic syndrome. Diabètes Res Clin Pract. 2009;84:84-91.

8. Amarapurkar D, Kamani P, Patel N, Gupte P, Kumar P, Agal S, et al. Prevalence of non-alcoholic fatty liver disease: population based study. Ann Hepatol. 2007;6:161-3. 
9. Adams LA, Lymp JF, St Sauver J, Sanderson SO, Lindor KD, Feldstein A, et al. The natural history of nonalcoholic fatty liver disease: a population-based cohort study. Gastroenterology. 2005;129:113-21.

10. Bugianesi E, Leone N, Vanni E, Marchesini G, Brunello F, Carucci $\mathrm{P}$, et al. Expanding the natural history of nonalcoholic steatohepatitis: from cryptogenic cirrhosis to hepatocellular carcinoma. Gastroenterology. 2002;123:134-40.

11. Caldwell SH, Crespo DM. The spectrum expanded: cryptogenic cirrhosis and the natural history of non-alcoholic fatty liver disease. J Hepatol. 2004;40:578-84.

12. Marchesini G, Brizi M, Bianchi G, Tomassetti S, Bugianesi E, Lenzi M, et al. Non-alcoholic fatty liver disease: a feature of the metabolic syndrome. Diabetes. 2001;50:1844-50.

13. Marchesini G, Brizi M, Morselli-Labate AM, Bianchi G, Bugianesi E, McCullough AJ, et al. Association of nonalcoholic fatty liver disease with insulin resistance. Am J Med. 1999;107:450-5.

14. Iyer SR. Type 2 diabetes express highway, where is the ' $U$ ' turn? J Assoc Physicians India. 2003;51:495-500.

15. Mohan V, Deepa R. Adipocytokines and the expanding 'Asian Indian Phenotype'. J Assoc Physicians India. 2006;54:685-6.

16. Misra A, Vikram NK. Insulin resistance syndrome (metabolic syndrome) and Asian Indians. Current Science. 2002;83:1483-96.

17. Marchesini G, Bugianesi E, Forlani G, Cerrelli F, Lenzi M, Manini $\mathrm{R}$, et al. Non-alcoholic fatty liver, steatohepatitis and the metabolic syndrome. Hepatology. 2003;37:917-23.

18. Cleeman JI. Executive summary of the third report of the National Cholesterol Education Program (NCEP) expert panel on detection, evaluation, and treatment of high blood cholesterol in adults (adult treatment panel III). JAMA. 2001;285:2486-97.

19. Sawant A, Mankeshwar R, Shah S, Raghavan R, Dhongde G, Raje $\mathrm{H}$, et al. Prevalence of metabolic syndrome in urban India. Cholesterol. 2011;2011:920983.

20. American Diabetes Association. Diagnosis and classification of diabetes mellitus. Diabetes Care. 2006;29:S43-S48.

21. Hui JM, Sud A, Farrell GC, Bandara P, Byth K, Kench JG, et al. Insulin resistance is associated with chronic hepatitis $\mathrm{C}$ virus infection and fibrosis progression. Gastroenterology. 2003;125:1695-704.

22. Misra A, Chowbey P, Makkar BM, Vikram NK, Wasir JS, Chadha D, et al., Consensus Group. Consensus statement for diagnosis of obesity, abdominal obesity and the metabolic syndrome for Asian Indians and recommendations for physical activity, medical and surgical management. J Assoc Physicians India. 2009;57:163-70.

23. Madan K, Batra Y, Gupta SD, Chander B, Rajan KD, Tewatia MS, et al. Non-alcoholic fatty liver disease may not be a severe disease at presentation among Asian Indians. World $J$ Gastroenterol. 2006;12:3400-5.

24. Saadeh S, Younossi ZM, Remer EM, Gramlich T, Ong JP, Hurley $\mathrm{M}$, et al. The utility of radiological imaging in nonalcoholic fatty liver disease. Gastroenterology. 2002;123:745-50.

25. Kleiner DE, Brunt EM, Van Natta M, Behling C, Contos MJ, Cummings OW, et al., Nonalcoholic Stteatohepatitis Clinical Research Network. Design and validation of a histological scoring system for nonalcoholic fatty liver disease. Hepatology. 2005;41:1313-21.

26. Park SH, Jeon WK, Kim SH, Kim HJ, Park DI, Cho YK, et al. Prevalence and risk factors of non-alcoholic fatty liver disease among Korean adults. $J$ Gastroenterol Hepatol. 2006;21:138-43.

27. Dassanayake AS, Kasturiratne A, Rajindrajith S, Kalubowila U, Chakrawarthi S, De Silva AP, et al. Prevalence and risk factors for non-alcoholic fatty liver disease among adults in an urban Sri Lankan population. J Gastroenterol Hepatol 2009;24:1284-8.

28. Duseja A, Das A, Dhiman RK, Chawla YK, Das R, Bhadada S, et al. Indian patients with nonalcoholic fatty liver disease presenting with raised transaminases are different at presentation. World $J$ Gastroenterol. 2007;13:649-50.

29. Agarwal SR, Malhotra V, Sakhuja P, Sarin SK. Clinical, biochemical and histological profile of nonalcoholic steatohepatitis. Indian $J$ Gastroenterol. 2001;20:183-6.

30. Torres DM, Harrison SA. Diagnosis and therapy of nonalcoholic steatohepatits. Gastroenterology. 2008;134:1682-98.

31. Fracanzani AL, Valenti L, Bugianesi E, Andreoletti M, Colli A, Vanni E, et al. Risk of severe liver disease in nonalcoholic fatty liver disease with normal aminotransferase levels: a role for insulin resistance and diabetes. Hepatology. 2008;48:792-8.

32. Margariti E, Deutsch M, Manolakopoulos S, Papatheodoridi GV. Non-alcoholic fatty liver disease may develop in individuals with normal body mass index. Ann Gastroenterol. 2012;25:45-51.

33. Amarapurkar DN, Patel ND. Clinical spectrum and natural history of non-alcoholic steatohepatitis with normal alanine aminotransferase values. Trop Gastroenterol. 2004;25:130-4.

34. Uslusoy HS, Nak SG, Gülten M, Biyujku Z. Non-alcoholic steatohepatitis with normal aminotransferase values. World $J$ Gastroenterol. 2009;15:1863-8.

35. Duseja A, Das A, Das R, Dhiman RK, Chawla Y, Bhansali A, et al. The clinicopathological profile of Indian patients with nonalcoholic fatty liver disease (NAFLD) is different from that in the West. Dig Dis Sci. 2007;52:2368-74.

36. Henao-Mejia J, Elinav E, Jin C, Hao L, Mehal WZ, Strowig T, et al. Inflammasome-mediated dysbiosis regulates progression of NAFLD and obesity. Nature. 2012;482:179-85.

37. Pyleris E, Giamarellos-Bourboulis EJ, Tzivras D, Koussoulas V, Barbatzas C, Pimentel M. The prevalence of overgrowth by aerobic bacteria in the small intestine by small bowel culture: relationship with irritable bowel syndrome. Dig Dis Sci. 2012;57:1321-9.

38. Sabaté JM, Jouët P, Harnois F, Mechler C, Msika S, Grossin M, et al. High prevalence of small intestinal bacterial overgrowth in patients with morbid obesity: a contributor to severe hepatic steatosis. Obes Surg. 2008;18:371-7.

39. Polyzos SA, Kountouras J, Papatheodorou A, Patsiaoura K, Katsiki E, Zafeiriadou E, et al. Helicobacter pylori infection in patients with nonalcoholic fatty liver disease. Metabolism. 2013;62:121-6.

40. Takuma Y. Helicobacter pylori infection and liver diseases. Gan To Kagaku Ryoho. 2011;38:362-4.

41. Soza A, Riquelme A, González R, Alvarez M, Pérez-Ayuso RM, Glasinovic JC, et al. Increased orocecal transit time in patients 
with nonalcoholic fatty liver disease. Dig Dis Sci. 2005;50:1136-40.

42. Pinidiyapathirage MJ, Dassanayake AS, Rajindrajith S, Kalubowila U, Kato N, Wickremasinghe AR, et al. Non-alcoholic fatty liver disease in a rural, physically active, low income population in Sri Lanka. BMC Res Notes. 2011;4:513.

43. Fernandes MT, Ferraro AA, de Azevedo RA, Fagundes NU. Metabolic differences between male and female adolescents with non-alcoholic fatty liver disease, as detected by ultrasound. Acta Paediatr. 2010;99:1218-23.

44. Haentjens P, Massaad D, Reynaert H, Peeters E, Van Meerhaeghe A, Vinken S, et al. Identifying non-alcoholic fatty liver disease among asymptomatic overweight and obese individuals by clinical and biochemical characteristics. Acta Clin Belg. 2009;64:483-93.

45. Spruss A, Henkel J, Kanuri G, Blank D, Püschel GP, Bischoff $\mathrm{SC}$, et al. Female mice are more susceptible to nonalcoholic fatty liver disease: sex-specific regulation of the hepatic AMP-activated protein kinase-plasminogen activator inhibitor 1-cascade, but not the hepatic endotoxin response. Mol Med. 2012;18:1346-55.

46. Ayonrinde OT, Olynik JK, Beilin LJ, Mori TA, Pennell CE, de Klerk N, et al. Gender-specific differences in adipose distribution and adipocytokines influence adolescent nonalcoholic fatty liver disease. Hepatology. 2011;53:800-9.

47. Armstrong MJ, Houlihan DD, Bentham L, Shaw JC, Cramb R, Olliff S, et al. Presence and severity of non-alcoholic fatty liver disease in a large prospective primary care cohort. $J$ Hepatol. 2012;56:234-40.

48. Sanyal AJ. American Gastroenterological Association. AGA technical review on non-alcoholic fatty liver disease. Gastroenterology. 2002;123:1705-25.

49. Day CP, James OF. Steatohepatitis: a tale of two "hits"? [Editorial]. Gastroenterology. 1998;114:842-5.

50. Chitturi S, Abeygunasekera S, Farrell GC, Holmes-Walker J, Hui JM, Fung C, et al. NASH and insulin resistance: insulin hypersecretion and specific association with the insulin resistance syndrome. Hepatology. 2002;35:373-9.

51. Ratziu V, Giral P, Charlotte F, Bruckert E, Thibault V, TheodorouI I, et al. Liver fibrosis in overweight patients. Gastroenterology. 2000;118:1117-23.

52. Kichian K, McLean R, Gramlich LM, Baily RJ, Bain VG. Nonalcoholic fatty liver disease in patients investigated for elevated liver enzymes. Can J Gastroenterol. 2003;17:38-42. 